\title{
Characterization of mesoporous zirconium and cerium oxides by transmission electron microscopy
}

\author{
M.A. Salvador*, J. Canales-Vázquez**, P. Ferreira* and F.M. Figueiredo* \\ * CICECO, Dept. of Ceramics and Glass Engineering, University of Aveiro, 3810-193 Aveiro, Portugal \\ ** Renewable Energy Research Institute, University of Castilla-la-Mancha, Albacete Science \& \\ Technology Park 02006, Albacete, Spain
}

Mesoporous materials have typical average pore diameters in the range $20-500 \AA$, which are usually accompanied by high specific surface area $\left(A_{\mathrm{BET}}\right)$ and large pore volume $\left(V_{\mathrm{p}}\right)$ with narrow pore size distributions[1]. These features are very attractive for potential application as catalysts and adsorbents[2]. Mesoporous materials are usually prepared by soft templating or nanocasting process. The latter approach is based on the replication of hard-templates, such as mesoporous silica (e.g. SBA-15), being a very flexible and suitable method to obtain stable and predictable pore mesostructures[3]. However, the chemical compatibility between the template and the precursors must be ensured.

In this work, the factors affecting the synthesis of mesoporous zirconium oxide $\left(\mathrm{ZrO}_{2}\right)$ and cerium oxide $\left(\mathrm{CeO}_{2}\right)$ by replication of SBA-15 are analysed with emphasis on the microstructural features and chemical interactions of Si with $\mathrm{Zr}$ or Ce.

The SBA-15 template, previously prepared by well established procedures[4], was impregnated with $\mathrm{ZrOCl}_{2}$ or $\mathrm{CeNO}_{3}$ aqueous solutions, and then fired at 600 and $550{ }^{\circ} \mathrm{C}$ to obtain SBA- $15 / \mathrm{ZrO}_{2}$ and SBA$15 / \mathrm{CeO}_{2}$, respectively. The corresponding transmission electron microscopy (TEM) images (Figures- 1a and $1 \mathrm{~b}$ ) reveal that not all pores were filled due to the precursor volume contraction. High resolution TEM (not shown) indicates that both $\mathrm{ZrO}_{2}$ and $\mathrm{CeO}_{2}$ crystallize with the cubic structure (possibly tetragonal in the case of zirconia). The $\mathrm{Si}: \mathrm{Zr}=1.97$ and $\mathrm{Si}: \mathrm{Ce}=3.44$ at ratios determined by EDS are in good agreement with the initial stoichiometric quantities (1.9 and 3.3), thus confirming the effectiveness of the impregnation.

The silica template was removed by repeatedly washing the powders with a $\mathrm{NaOH} 2 \mathrm{M}$ aqueous solution, with the $\mathrm{Si}$ content decreasing down to typical residual values corresponding to $\mathrm{Si}: \mathrm{Zr}=0.17$ and $\mathrm{Si}: \mathrm{Ce}=0.12$. While $\mathrm{Si}$ could not be completely removed, its content was systematically found to be larger in $\mathrm{ZrO}_{2}$ than in $\mathrm{CeO}_{2}$. Moreover, while no apparent structural changes were observed on $\mathrm{CeO}_{2}$, a progressive increase of the quantity of zirconium oxide nanoparticles with the monoclinic structure was apparent with decreasing Si content (Figures 1e), also confirmed by X-ray diffraction (not shown). However, the most striking difference between the two materials is the complete loss of pore order in the zirconia (Figure 1c), whereas the ceria appears as a nearly perfect inverse replica of the SBA-15 hexagonal pore structure (Figure 1d).

These results suggest a strong chemical interaction between the $\mathrm{SiO}_{2}$ template and the $\mathrm{Zr}$, as revealed by the presence of Zr-O-Si bands in Fourier transform infrared (FTIR) spectra (Figure 2c). On the contrary, there is no evidence for Ce-O-Si cross-linking[5].

In summary, mesoporous $\mathrm{ZrO}_{2}$ and $\mathrm{CeO}_{2}$ can be obtained by replication of SBA-15 silica hard templates. However, $\mathrm{ZrO}_{2}$ shows a disordered mesostructure after removal of the template. This result is in disagreement with the results obtained by Liu et al. [6], who reported a $\mathrm{Si} / \mathrm{Zr}$ atomic ratio of 0.36 in their final product, whereas we obtain only 0.17 . This suggests that the $\mathrm{ZrO}_{2}$ ordered porous structure reported in [6] may be kept due to the presence of silica or a $\mathrm{Si}-\mathrm{Zr}$ reaction product. On the contrary, an exact 
negative replica of the ordered SBA-15 was obtained for $\mathrm{CeO}_{2}$, with no apparent reaction between $\mathrm{Si}$ and Ce.

\section{References}

1. Rouquerol et al., Pure \& Appl. Chem 66: 1739-1758, 1994

2. Hoffmann et al., Angew. Chem. Int. Ed. 45 (20): 3216-3251, 2006

3. Tiemann, Chem. Mater. 20 (3): 961-971, 2008

4. Zhao et al., J. Am. Chem. Soc. 120: 6024-6036, 1998

5. Mohamed et al., 93: 71-81, 2006

6. Liu et al., J. Mater. Chem. 18: 5200-5207, 2008

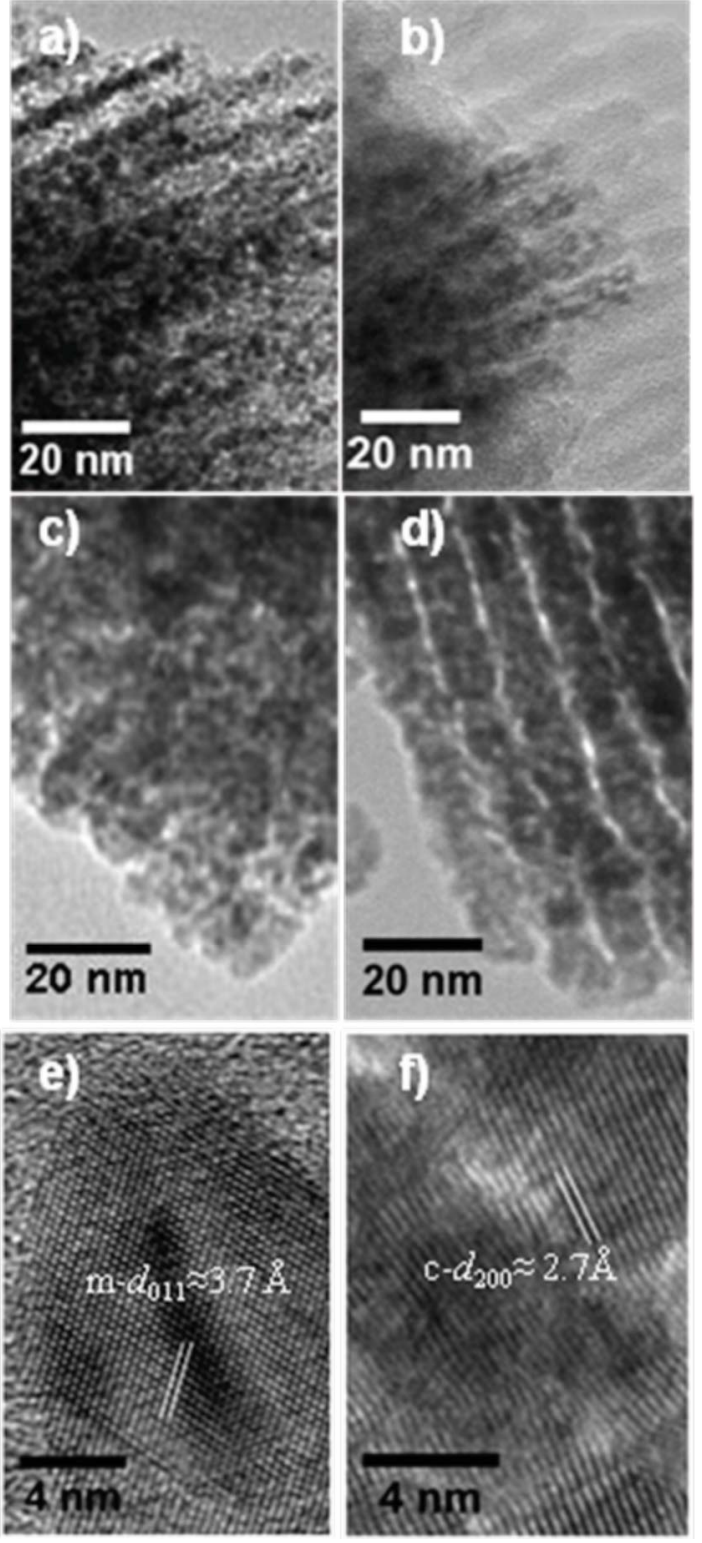

Figure 1. TEM images of (a) SBA15/ZrO2, (b) SBA-15/CeO2, (c) $\mathrm{ZrO} 2$, (d) $\mathrm{CeO} 2$. HRTEM images of (e) $\mathrm{ZrO} 2$ and

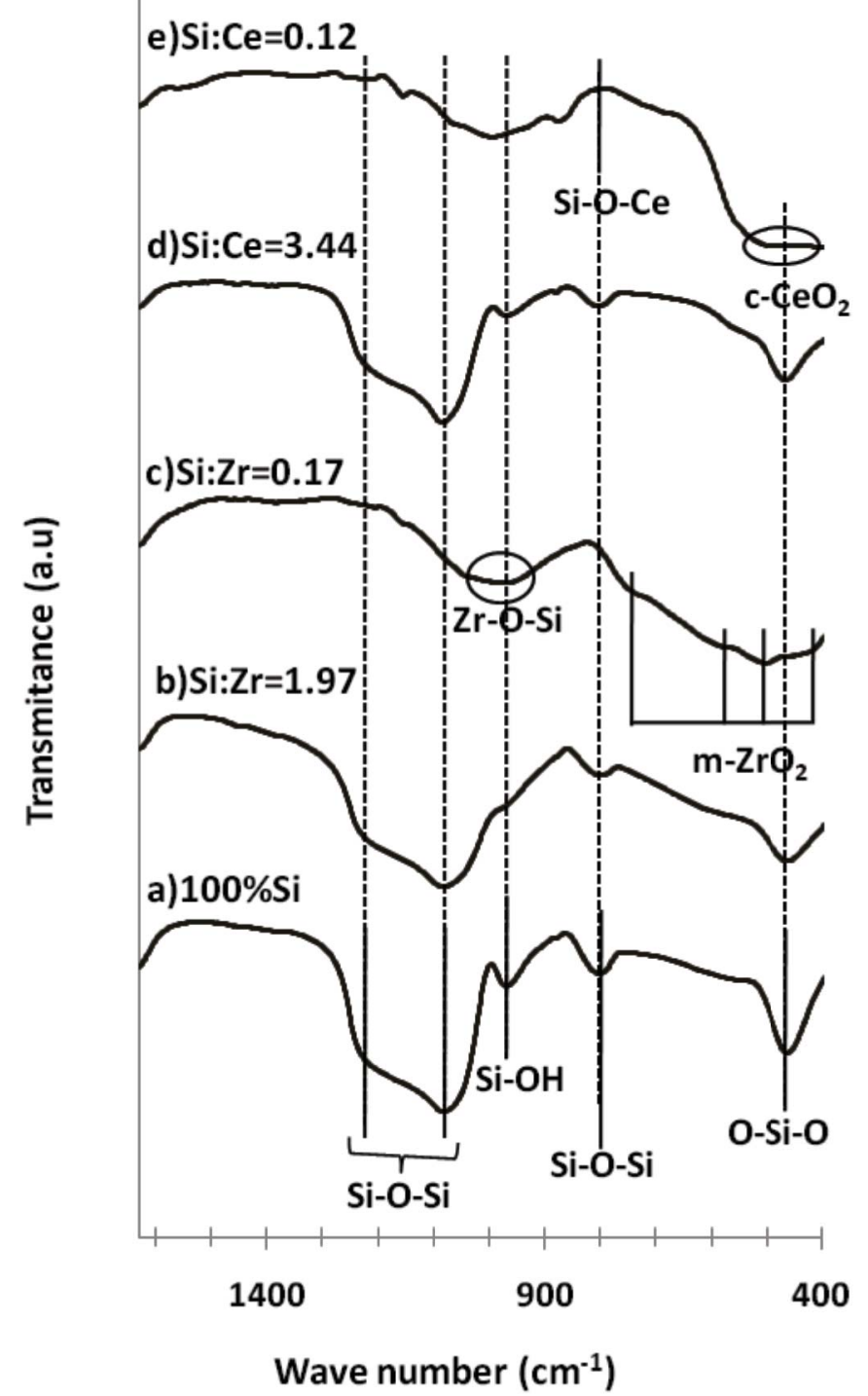

Figure 2. FTIR spectra of (a) SBA-15, (b) $\mathrm{SBA}-15 / \mathrm{ZrO} 2$, (c) $\mathrm{ZrO} 2$, (d) SBA$15 / \mathrm{CeO} 2$ and (e) $\mathrm{CeO} 2$. 